
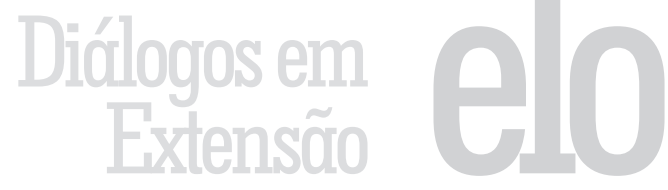

\title{
Um projeto de extensão voltado para o incentivo à leitura de obras literárias e cinematográficas: o caso do Instituto Federal do Espírito Santo
}

Ráisa Mendes Fernandes de Souza $a^{1}$, Diogo Pereira Matos², Elisa Canuta da Silva ${ }^{3}$, Laíze Dalla Bernardina Monteiro ${ }^{4}$

Resumo: O projeto, realizado no Instituto Federal do Espírito Santo (IFES), campus Ibatiba, pelos setores Núcleo Pedagógico e Biblioteca, tem como proposta inicial investigar o papel exercido pelas obras cinematográficas na fixação de conteúdo das obras bibliográficas relacionadas. Esse projeto foi criado mediante a necessidade de mais iniciativas voltadas para a leitura, além da importância de potencializar o acervo da Biblioteca. Tem como objetivos específicos despertar nos alunos participantes o senso crítico sobre filmes originados de obras literárias; contribuir para o incentivo à leitura de obras bibliográficas e cinematográficas e analisar as contribuições das obras cinematográficas como instrumento pedagógico. O projeto será composto por oito encontros, destinados à discussão dos dois tipos de obras. Acredita-se que o projeto servirá de insumo para futuros trabalhos ligados à leitura e aprendizagem.

Palavras chave: Cinema, educação, incentivo à leitura, Instituto Federal do Espírito Santo.

Áreas temáticas: Cultura eeducação.

\section{An extension project aimed to encourage reading of books and movies: the case of the Federal Institute of Espirito Santo}

Abstract: The project, carried out at the Federal Institute of Espirito Santo, Ibatiba campus, by sectors Core Teaching and Library, has the initial proposal of investigating the role played by films in helping to understand the content of bibliographic original works. This project was created by the need of more initiatives for reading and the importance of enhancing the Library's collection. Its specific objectives are to foster in students participating in critical thinking about films originated from literary works; contribute to encourage reading of literature and film and analyze the contributions of cinematographic works as

\footnotetext{
1 Bibliotecária do Instituto Federal do Espírito Santo.Endereço: Instituto Federal do Espírito Santo - Campus Ibatib, Avenida Sete de Novembro,nº.40 - Centro. Ibatiba - ES. E-mail: raisamendess@ gmail.com.br.

2 Pedagogo do Instituto Federal do Espírito Santo.

${ }^{3}$ Bibliotecária do Instituto Federal do Espírito Santo.

${ }^{4}$ Psicóloga do Instituto Federal do Espírito Santo.
} 
an educational tool. The project will consist of eight meetings for the discussion of the two works. It is believed that the project will serve as input for future work related to reading and learning.

Keywords: Cinema, education, encourage reading, Federal Institute of Espírito Santo

\section{Un proyecto de extensión dirigido a fomentar la lectura de obras literarias y cinematográficas: el caso del Instituto Federal del Espírito Santo}

Resumen: El proyecto, llevado a cabo en el Instituto Federal do Espírito Santo, campus Ibatiba, por sectores Núcleo Pedagógico y Biblioteca, tiene la propuesta inicial para investigar el papel de las películas en la fijación de los contenidos de las obras originales bibliográficas. La creación de este proyecto estuvo a cargo de la necesidad de más iniciativas para la lectura y la importancia de la mejora de la colección de la Biblioteca. Sus objetivos específicos son promover en los estudiantes que participan en el pensamiento crítico acerca de las películas originadas en las obras literarias, contribuyen a fomentar la lectura de obras de la literatura y el cine y analizar las contribuciones de las obras cinematográficas como una herramienta educativa. El proyecto constará de ocho reuniones para la discusión de los diferentes tipos de obras. Se cree que el proyecto servirá de insumo para el trabajo futuro relacionado con la lectura y el aprendizaje.

Palabras clave: Cine, educacion, fomento de la lectura, Instituto Federal do Espírito Santo.

\section{Introdução}

A Rede Federal de Educação Profissional, Científica e Tecnológica instituída pela Lei $\mathrm{n}^{\circ}$ 11.892, de 29 de dezembro de 2008, criou o Instituto Federal de Educação, Ciência e Tecnologia do Espírito Santo - IFES, mediante a integração do Centro Federal de Educação Tecnológica do Espírito Santo e das Escolas Agrotécnicas Federais de Alegre, de Colatina e de Santa Teresa (BRASIL, 2013).

O IFES é uma instituição de educação superior, básica e profissional, pluricurricular, multicampi e descentralizada, especializada na oferta de educação profissional e tecnológica nas diferentes modalidades de ensino, com base na conjugação de conhecimentos técnicos e tecnológicos com suas práticas pedagógicas. Mais do que um espaço de capacitação profissional, o Instituto Federal do Espírito Santo é um ambiente de aprendizagem e de desenvolvimento integral, assumindo como principal desafio a promoção de uma educação plena por meio da diversificação das atividades extracurriculares (BRASIL, 2013). 
Com o intuito de estender a rede pública de educação técnica e tecnológica profissionalizante para o sul do Estado do Espírito Santo, o campus Ibatiba foi criado em novembro de 2010. Contava inicialmente com os Cursos Técnicos Integrados com o Ensino Médio de Meio Ambiente, nos turnos matutino e vespertino.

Atualmente, as atividades do IFES campus Ibatiba dividem-se em duas gestões: Gestão do Ensino e Gestão Administrativa. Subordinada à Gestão do Ensino encontra-se o Núcleo Pedagógico, setor esse que possui uma gama de profissionais, constituída por professores, pedagogos, assistentes sociais, coordenadores dos cursos, uma psicóloga e um assistente administrativo. Esse setor é responsável pela organização do ensino, o que envolve a elaboração das matrizes curriculares e distribuição de seus respectivos componentes, além dos horários dos docentes, visando otimizar as condições de aprendizado e formação do corpo docente.

A Biblioteca do campus, por sua vez, é subordinada ao Núcleo Pedagógico e também participa de determinados encontros e reuniões organizados pelo Núcleo e em conjunto com os docentes. A Biblioteca possui atualmente um acervo composto por em torno de 1500 exemplares, sendo esses dicionários, enciclopédias, revistas, livros técnicos e romances. Todavia, mesmo diante da complexidade, extensão e longevidade do Instituto, poucas iniciativas voltadas para o incentivo à leitura, as quais tivessem o setor da Biblioteca como participante, foram identificadas, principalmente em forma de projetos de extensão.

O presente estudo de caso trata-se de um projeto de extensão, com teor investigativo, elaborado pela Biblioteca e Núcleo Pedagógico do IFES campus Ibatiba, o qual foi submetidoao edital interno 001/2013 e aprovado em $1^{\circ}$ lugar, com vistas a ser iniciado no mês de setembro de 2013.

A realização do projeto de extensão justifica-se pela necessidade de criação de mais iniciativas voltadas para a leitura, principalmente dentro do IFES campus Ibatiba, de forma mais dinâmica e enriquecedora, ampliando assim o uso de materiais audiovisuais como ferramenta pedagógica. Faz-se necessário também, criar maneiras de potencializar o acervo da biblioteca, que até então não tem sido utilizado pelos alunos da forma esperada. Outro aspecto interessante seria o incentivo ao contato dos alunos com tais materiais culturais e artísticos, uma vez que existe um diálogo entre a arte literária e a arte cinematográfica.

Por fim, acredita-se que a realização desse projeto seja inclusive de suma importância para a participação do Núcleo Pedagógico (sendo representado pela psicóloga e pedagogo do campus) e da Biblioteca (sendo representada por uma das bibliotecárias) em atividades pedagógicas mais próximas dos alunos, contribuindo assim para uma integração da escola. 


\section{Problemas e objetivos do projeto}

O projeto de extensão foi elaborado aos moldes de uma pesquisa científica, sendo assim, o mesmo apresenta como problema de pesquisa identificar o papel exercido pelas obras cinematográficas na fixação de conteúdo de obras bibliográficas originais.

O objetivo geral do projeto é o de avaliar o papel exercido pelas obras cinematográficas na fixação de conteúdo das obras bibliográficas originais, tendo como objetivos específicos despertar nos alunos participantes o senso crítico sobre filmes originados de obras literárias; incentivar a leitura de obras bibliográficas e cinematográficas e avaliar as contribuições das obras cinematográficas como instrumento pedagógico.

\section{Fundamentação teórica}

De acordo com Dias (2007), desde o nosso nascimento somos constantemente desafiados a interpretar as linguagens imagéticas que a todo o momento recebemos, seja por meio de revistas, jornais, televisão, internet, entre outras. Bosi (1988, p.65, apud ZUNTIM, 2009, p.23) afirma que "os psicólogos da percepção são unânimes em afirmar que a maioria absoluta das informações que o homem moderno recebe lhe vem por imagens. O homem de hoje é um ser predominantemente visual". Diante disso, pode-se considerar a imagem como um dos meios de informação mais utilizados pelo homem como ferramenta de aprendizagem.

Prosseguindo na ideia de Dias (2007), antes mesmo de adentrarmos no mundo verbal, estamos intimamente ligados ao sensorial, ao imagético, ao não-verbal. Em vista disso, é inegável considerar a imagem como importante fator relacionado com a fixação das informações e mensagens captadas a todo o momento. Porém, com o advento das novas tecnologias, a captação de imagens foi reconfigurada, pois, segundo Soares (2010), as profundas mudanças científicas e tecnológicas ocorridas no século XXI suscitaram novas problemáticas relacionadas com as recentes linguagens que a tecnologia tornou possível. A autora prossegue afirmando que estudos contemporâneos mostram que estas transformações estão criando uma nova cultura e modificando as formas de produção e apropriação dos saberes.

Recursos "tecno-pedagógicos" envolvendo linguagens imagéticas são utilizados em sala de aula com certa frequência, seja na apresentação de slides em powerpoint, seja na exibição de pequenos vídeos ou mesmo na utilização da TV e exibição de DVDs de uma forma geral. Entretanto, Daminelli (2010) afirma que é notável que a utilização desses recursos como suporte ao uso da sétima arte (o cinema) e como recursos no processo de aprendizagem nas escolas, ainda é muito incipiente. Martins 
(1993, apud DIAS, 2007) justifica essa deficiência afirmando que a escola ainda restringe a noção de leitura a um processo racional de atribuição de significado à palavra escrita.

O cinema, em forma de obras cinematográficas, pode ser utilizado como ferramenta de integração entre o processo ensino-aprendizagem.

Os caminhos do cinema se cruzam com os caminhos da educação no horizonte das expectativas pedagógicas. A relação entre cinema e educação não é um aspecto contemporâneo, existe desde 1895. Foi a partir desta relação que a indústria cinematográfica passou a ser considerada, desde sempre, um instrumento de educação. [...] A relação entre cinema e educação deu origem a um largo debate sobre a utilização do cinema como veículo e ferramenta de ensino-aprendizagem (DAMINELLI, 2010, p.58).

Através das obras cinematográficas, o aluno constrói uma perspectiva crítica para abordar o texto literário de um modo sensível e inteligente. De acordo com Napolitano (2003, p.60), "não dá para negar a função pedagógica que o cinema desempenha hoje. Sua utilização na escola pode contribuir para o desenvolvimento da linguagem, do pensamento e de habilidades leitoras."

Segundo Soares (2010) cabe à escola, ainda que não exclusivamente, a responsabilidade de praticar a leitura e de formar leitores, já que é necessário desenvolver esta competência ao longo do percurso escolar dos alunos. Posto isso, considera-se a relevância de explorar mais o cinema, em forma de obras cinematográficas, no auxílio à leitura e interpretação das obras literárias.

A literatura e o cinema são dois campos artísticos que têm realizado uma relação ampla de mútua contribuição. Podemos perceber que muitos estudos aplicados à literatura têm sua abrangência estendida ao cinema, principalmente sobre personagens, assim como também é notável a assimilação de termos cinematográficos por parte da literatura, como flash-back, narrador-câmera etc. (MOURA, 2009, online, p.4).

As linguagens imagéticas de obras cinematográficas ajudam na compreensão da obra literária sob a ótica de outra pessoa. Isso possibilita uma comparação das diferentes ideias do autor e a analise de como uma mesma história pode ter várias interpretações. Isso é possível por que de acordo com Amorim (2010, p.173, apud ALVES, 2013, p.20) o cinema e a literatura são "estruturas da linguagem. Desta forma não se excluem, pelo contrário, se completam."

Feita a exposição do embasamento teórico da pesquisa, segue a metodologia que será utilizada para a realização do projeto. 


\section{Metodologia e estratégia de ação}

Trata-se de um projeto de extensão de cunho investigativo do tipo qualitativo, pois busca, por meio da discussão e aplicação de questionários aos alunos participantes, compreender a influência de filmes no entendimento de suas respectivas obras originais. Os alunos foram selecionados de acordo com o bom desempenho no histórico curricular, disponibilidade para comparecer aos encontros presenciais e interesse pela proposta do projeto.

Acredita-se que o período de um mês será o suficiente para que todos os envolvidos no projeto possam ler e analisar cada obra bibliográfica (a qual será previamente informada). O projeto será composto por oito reuniões com duração de três horas cada, as quais serão realizadas mensalmente até a finalização do projeto.

As oito obras serão indicadas por oito professores de modo que cada docente irá escolher uma obra que possa auxiliar na compreensão da sua disciplina. Assim, cada aluno terá direito a certa pontuação extra nas disciplinas dos professores participantes, com prévia anuência dos mesmos.

Em cada reunião será exibida, primeiramente, uma apresentação do contexto histórico e estilo da obra literária e curiosidades sobre a obra cinematográfica. Tais apresentações serão elaboradas pelo bolsista do projeto, utilizando o acervo da biblioteca (revistas sobre cinema, livros sobre estilos literários, etc) como apoio no intuito de contextualizar os demais participantes. Após a apresentação, será exibido um dos filmes selecionados e após a apresentação da obra cinematográfica serão discutidos os pontos convergentes e divergentes das duas obras.

Em seguida, serão aplicados questionários mistos aos alunos afim de captar qual foi o papel daquele filme para a fixação de conteúdo da obra literária.

Em linhas gerais, os procedimentos metodológicos do projeto serão compostos pelas seguintes etapas:

- Identificar, junto aos professores, quais são as obras literárias, nacionais e estrangeiras, que poderiam auxiliar em suas respectivas disciplinas;

- Selecionar, dentre as obras identificadas na primeira etapa, oito obras literárias que possuam alguma adaptação do cinema;

- Verificar se tais obras literárias estão disponíveis para empréstimo no sistema Pergamum do Instituto;

- Selecionar cinco alunos do IFES- Campus Ibatiba- que tenham interesse em participar da pesquisa; 
- Agendar e realizar reuniões mensais, cujo horário não conflite com o horário de aula dos alunos participantes, onde serão exibidos os filmes e discutido o seu conteúdo;

- Aplicar, logo após a discussão, questionários mistos aos alunos envolvidos;

- Analisar os resultados obtidos.

\section{Resultados e impactos esperados}

Acredita-se que a inserção do cinema seja uma alternativa mais dinâmica e enriquecedora em atividades de incentivo à leitura, principalmente quando tratar-se de filmes originados de livros. Acredita-se que o projeto servirá para despertar o interesse das demais Bibliotecas e Núcleos de outros campi a desenvolverem projetos de extensão no tocante à promoção da leitura.

É importante ressaltar, também, que os resultados dessa pesquisa servirão de insumos para futuros trabalhos ligados à leitura e aprendizagem, que tenham como foco a análise de obras cinematográficas como ferramenta pedagógica.

\section{Referências Bibliográficas}

ALVES, M.W. Inserção de livros de literatura e de filmes cinematográficos no acervo da biblioteca da Eletrosul. Florianópolis, SC: [s.e.], 2013. Disponível em: https://repositorio.ufsc.br/bitstream/ handle/123456789/103798/TCC\%20M\%C3\%B4nica\%20W.\%20 Alves.pdf?sequence=1. Acesso em: 27 ago. 2013.

BRASIL. Ministério da Educação. Relatório de gestão do exercício de 2012. Disponível em: http://www.ifes.edu.br/images/stories/files/ Institucional/Relatorio_Gestao_2012.pdf. Acesso em: 12 ago. 2013.

DAMINELLI, S. A contribuição de filmes legendados para o ensino da leitura. 97 f. 2010. Dissertação (Mestrado em Estudos da Tradução) - Centro de Comunicação e Expressão, Universidade Federal de Santa Catarina, Florianópolis, 2010. Disponível em: http://repositorio.ufsc.br/xmlui/ bitstream/handle/123456789/94426/276929.pdf? sequence $=1$. Acesso em: 06 jun. 2013.

DIAS, L.A.X. Cinema e educação: uma leitura semiótica de "O enigma de Kaspar Hauser”, de Werner Herzog. In: XVI CONGRESSO DE LEITURA NO BRASIL, 15., 2007, São Paulo, Campinas. Anais eletrônicos...São Paulo, Campinas: ALB, 2007. Disponível em: http://alb. com.br/arquivo-morto/edicoes_anteriores/anais16/sem05pdf/ sm05ss04_09.pdf. Acesso em: 04 jun. 2013. 
MARTINS, M.H. (Org.) Questões de linguagem. $3^{\mathrm{a}}$ ed. São Paulo: Contexto, 1993.

MOURA, A.R.; FILETTI, E. Literatura e cinema: possibilidades de leitura em sala de aula. In: $17^{\circ}$ CONGRESSO DE LEITURA NO BRASIL, 17. 2009, Campinas, São Paulo. Anais... Campinas, São Paulo: Unicamp, 2009. Disponível em: http://alb.com.br/arquivo-morto/edicoes_ anteriores/anais17/txtcompletos/sem04/COLE_562.pdf. Acesso em: 27 agos. 2013

NAPOLITANO, M. Como usar o cinema na sala de aula. São Paulo: Contexto, 2008.

SOARES, M. A importância da leitura no mundo contemporâneo. Ozarfaxinars, Matosinhos, n.16, 2010.

ZUTIM, S. Notícia virtual:um olhar sobre a linguagem imagética. Rio Claro, RJ: [s.e.], 2009. Disponível em: http://www.educadores.diaadia. pr.gov.br/arquivos/File/2010/artigos_teses/2010/Arte/dissertacao/ noticia_virt.pdf. Acesso em: 27 ago. 2013. 